\title{
LEI, TRADIÇÃO E MEMÓRIA NA CONTROVERSA SUCESSÃO DE AFONSO X
} (1252-1284)

\section{LAW, TRADITION AND MEMORY IN THE CONTROVERSIAL SUCESSION OF AFONSO X (1252-1284)}

\author{
Adriana Vidotte* \\ Adailson José Rui ${ }^{* *}$
}

\begin{abstract}
Resumo:
O processo de sucessão de Afonso X, o Sábio, rei de Leão e Castela entre os anos de 1252 e 1284, foi controversa e colocou em questão a legitimidade do poder de seus sucessores. Esse processo, que se prolongou no tempo, será analisado por meio de um estudo dos relatos contidos na Crónica del Rey Don Alfonso Décimo, escrita durante o reinado de Afonso XI (1312-1350), e das leis da Siete Partidas, código jurídico elaborado no século XIII sob a direção de Afonso $\mathrm{X}$. Por meio do estudo e da confrontação das fontes analisaremos, por um lado, uma teoria sobre o poder régio e a sucessão ao trono, e por outro, uma prática que buscava manter a unidade do reino e a afirmar da legitimidade do poder dos monarcas.
\end{abstract}

Palavras Chave: Afonso X, Sucessão Real, Idade Média.

\begin{abstract}
:
The succession process of Alfonso X, the Wise, King of León and Castile between the years 1252 and 1284, was controversial and brought into question the legitimacy of his successors' power. This process, which extended in time, will be analyzed through a study of the reports contained in the Crónica del Rey Don Alfonso the Tenth, written during the reign of Alfonso XI (1312-50), and of the laws of Siete Partidas, legal code made in the thirteenth century under the direction of Alfonso X. Through the study and confrontation of sources, on the one hand, we will analyse a theory of the royal power and the succession to the throne and, on the other, a practice that sought to maintain the unity of the kingdom and to affirm the legitimacy of the power of the monarchs.
\end{abstract}

Key Words: Alfonso X, Royal Succession, Middle Ages.

\footnotetext{
* Professora na Graduação e na Pós Graduação em História da Universidade Federal de Goiás e no Mestrado Profissional em História Ibérica da Universidade Federal de Alfenas. E-mail: adrianavidotte@gmail.com

** Coordenador e docente do Mestrado Profissional em História Ibérica da Universidade Federal de Alfenas. Email: aj.rui@terra.com.br
} 


\section{INTRODUÇÃO}

Afonso X, o Sábio, rei de Leão e Castela entre os anos de 1252 e 1284, assumiu o trono após a morte de seu pai, Fernando III, o Santo. Casado com D. Violante, teve vários filhos legítimos, dos quais os dois primeiros, Fernando e Sancho, foram os principais personagens nos conflitos pela herança do trono. O problema sucessório de Afonso X começou antes mesmo da morte do rei. As disputas se iniciaram em 1275, quando o primogênito e herdeiro do trono, Fernando de la Cerda, morreu, em Ciudad Real, quando se dirigia à fronteira para defender o reino cristão do avanço dos invasores benimerines. A morte do herdeiro do trono, que possuía dois filhos legítimos, abriu um processo de disputas pelo trono, iniciado por seu irmão, Sancho - futuro Sancho IV. Esse processo colocaria em choque as regras de sucessão definidas na Siete Partidas - código de leis elaborado a mando do rei Sábio - e os interesses da aristocracia e do reino castelhano.

\section{O REI E A SUCESSÃO RÉGIA NAS SIETE PARTIDAS}

Elaborado, no século XIII, sob a direção de Afonso X, o Libro de las Leyes, mais conhecido como Las Siete Partidas, contém as leis que deveriam reger o reino de Castela. Conforme indica o título com o qual ficou conhecida, sete são as partes que compõem a obra, cada uma constituída por um conjunto de leis referentes a um assunto específico. A primeira parte trata da religião; a segunda da realeza; a terceira da administração da justiça; a quarta do matrimônio; a quinta dos contratos; a sexta dos testamentos; e a sétima dos delitos e penas. ${ }^{1}$

As leis que tratam sobre o rei e o poder por ele exercido encontram-se na Segunda Partida. $^{2}$ A Lei 5 do Título I da referida Partida expressa que os reis são Vigários de Deus colocados cada um em seu reino, tendo por missão a manutenção da justiça e da verdade. A função a ser desempenhada pelo rei é equiparada a realizada pelo imperador em seu império, revelando o modelo administrativo seguido por aqueles que elaboraram tal lei, ou seja, a noção de Império era o referencial a ser seguido no espaço do reino. ${ }^{3}$

A ideia do poder atribuído ao rei pela condição de vigário de Deus é fundamentada em referências espirituais e temporais. Em relação às primeiras, encontram sustentação nos feitos e dizeres dos profetas e dos santos, aos quais, segundo os elaboradores da lei, Deus havia concedido o conhecimento sobre o papel a ser desempenhado na função régia. ${ }^{4}$ Quanto às 
segundas referências, o texto apoia-se na autoridade dos homens sábios, representados entre outros por pensadores da antiguidade, como Cícero e Sêneca. Estes filósofos haviam tratado, entre outras temáticas, da construção ideal do príncipe romano. Ao apresentarem o rei como vigário de Deus, os autores da Segunda Partida conferiam ao rei o poder temporal e o espiritual, construindo, assim, uma imagem da realeza segundo a qual "o rei era um representante de Deus ante seus súditos, por Ele eleito para a realização de um plano político, de concepção divina, não carente de consequências religiosas" (NIETO SORIA: 1988; p. 100).

A condição de vigário de Deus é reafirmada na Lei 7 do Título I da mesma Partida. Essa lei, além de apresentar o rei como aquele que ocupa em seu reino o lugar de Deus para fazer a justiça, coloca em destaque a hereditariedade como forma de acesso à função régia. Contudo, a Lei 9 do mesmo Título I indica que a herança não era a única forma admitida para se tornar rei. A referida lei expõe que podiam ser chamados de reis aqueles que alcançassem essa condição pelo direito, e isso podia se dar de quatro formas: a primeira, por herança, quando o filho mais velho ou algum dos parentes mais próximos do rei herdasse o trono após a sua morte; a segunda, por consentimento dos habitantes do reino, os quais escolheriam seu senhor quando não houvesse nenhum parente do monarca defunto com direito à herança; a terceira, por matrimônio, quando um homem se casasse com a herdeira do rei defunto, isso na ausência de um filho herdeiro; a quarta, por designação do Papa ou do Imperador, quando estes nomeassem reis nas terras em que eram senhores.

Destaque-se que a herança era a forma primeira da sucessão régia. Para garantir e justificar a transmissão do poder ao filho primogênito do rei, a Segunda Lei do Título XV especifica que o fato de nascer primeiro era a forma como Deus deixava claro, para todos os habitantes do reino, que aquele deveria deter o direito ao trono. Conforme a lei:

\footnotetext{
Mayoria en nascer primero es muy gran señal de amor que muestra Dios a los hijos de los reyes, aquellos que Él les da, entre lo otros sus hermanos que nacen después de El. Ca, aquél a quien esta honra quiere hacer, bien da a entender que lo adelanta y lo pone sobre los otros, por que Le deben obedecer y guardar así como a padre y a señor.
}

O primogênito era o escolhido por Deus para reinar e caberia a todos, especialmente a seus irmãos menores, a obrigação de obedecê-lo e protegê-lo, assim como se obedece ao pai e ao senhor. O direito concedido ao primogênito justifica-se, também, pelo desejo de evitar a divisão do reino. 
Otrosi según antigua costumbre, como quiera que los padres habían piedad comunalmente de los otros hijos, no quisieron que el mayor los hubiese todo, mas que cada uno de ellos hubiese su parte. Pero con todo eso, los hombres sábios y entendidos, catando el pro comunal de todos, y conociendo que esta partición no se podría hacer en los reinos, que destruídos no fuesen, según que Nuestro señor Jesucristo dijo que todo reino partido seria estragado, tuvieron por derecho que el señorio del reino no lo hubiese sino el hijo mayor, después de la muerte de su padre. $Y$ esto usaron siempre en todas las tierras del mundo, doquier que el señorio hubieron por linaje, y mayormente en España.

A legislação apresentada nas Partidas, nesse aspecto, visava extinguir a prática de repartir o reino entre os herdeiros após a morte do rei, buscando, dessa forma, garantir a manutenção da unidade territorial. Para reforçar e justificar essa ideia, os autores da lei explicam que, de acordo com a tradição, era costume os pais dividirem os seus bens de forma comum entre seus filhos. No entanto, os sábios teriam percebido que essa prática não promovia o bem da comunidade, ao contrário, conduzia à divisão do reino, levando-o à sua destruição. Além disso, de acordo com autores das Partidas, esses sábios teriam levado em consideração as palavras atribuídas a Jesus Cristo, pelas quais o Deus Filho teria afirmado que todo reino dividido seria estragado/destruído. Diante disso, os elaboradores das Partidas tiveram por direito que o senhorio do reino pertenceria ao primogênito, somente após a morte do rei, seu pai. Esses elaboradores afirmam que essa era a prática em todo o mundo, principalmente na Espanha.

Ponto fundamental para a nossa discussão se revela na referida Segunda Lei do Título XV:

\footnotetext{
$Y$ por excusar muchos males que acaecieron y podrían aún ser hechos pusieron que el señorio del reino heredasen siempre aquéllos que viniesen por la línea derecha. $Y$ por ende, establecieron que si hijo varón alli no hubiese, la hiha mayor heredase el reino, y aun mandaron que si el hijo muriese antes que heredase, si dejase hijo o hija que hubiese de su mujer legitima, que aquél o aquella lo hubiese, y no outro ninguno. Pero si todos éstos falleciesen, debe heredar el reino el más propincuo pariente que hubiese, siendo hombre para ello, no habiendo hecho cosa porque lo debiese perder. (grifos nossos)
}

Ficava assim estabelecido que, para evitar problemas, o senhorio do reino seria herdado sempre por linha direta. Em caso de morte daquele que por herança estivesse designado a ser rei, e caso ele deixasse filho ou filha com sua legítima mulher, o filho ou a filha seriam considerados seus legítimos herdeiros.

Contudo, a questão sucessória nas Partidas é ponto polêmico na historiografia. Questiona-se, por um lado, a data em que o direito de sucessão tal como escrito na Lei 2 teria R. Fac. Dir. UFG, v. 40, n.2, p. 92-110, jul. / dez. 2016 
sido estabelecido no corpo das Partidas e, por outro, se as Partidas chegaram a ser promulgadas como lei durante a vida do rei Sábio. Embora a profundidade do debate levado a cabo por grandes especialistas, as dúvidas sobre a questão ainda permanecem. ${ }^{5}$ Não há consenso sobre em que momento as determinações sobre a sucessão real foram explicitadas pela primeira vez nas Partidas e em quais circunstâncias teriam sofrido modificações. Para Nuno Pizarro Dias (1998; p. 1355),

\begin{abstract}
O referido direito pode perfeitamente ter existido na versão original, como ter sido interpolado em finais de 1266 ou pouco depois, em conformidade com certas cláusulas do tratado de casamento de D. Fernando e Dona Branca, ou ainda no período de 1282 a 1284, em apoio das disposições testamentárias de Afonso X. Do mesmo modo que foi rescrito, talvez nos anos de 1276 a 1281, ou posteriormente, com a interpolação favorável aos direitos de Sancho IV.
\end{abstract}

Sobre a questão da vigência das Partidas em vida de Afonso X, um forte argumento foi apresentado por O'Callaghan (1966; p. 62) ao afirmar que elas estavam plenamente vigentes, fosse por promulgação ou ato da corte do rei, coisa incerta, ou pelo fato de ser uma revisão ampliada do Espéculo, código anterior, promulgado em Palencia em 1255. Assim, não seria necessário que as Partidas fossem promulgadas por separado, e elas tiveram, portanto, força de lei durante o reinado de Afonso X.

Manuel González Jiménez (1996-1997; p. 203) reforça a tese de que as Partidas estavam vigentes em tempos de Afonso $\mathrm{X}$, inclusive no que se refere à questão sucessória. González Jimenez, lembra que R. S. MacDonald, responsável por uma edição do Espéculo outra obra legislativa do período - na década de 1960, trouxe à luz manuscritos da Segunda Partida em que se alteravam o sentido da Lei 2 do Título XV: onde se lê "sy el fijo mayor moriese ante que heredase, sy dexase fijo o fija que oviese de muger legítima, que aquel o aquella lo oviese, e non otro ninguno" foi feita a seguinte interpolação: "si el fijo mayor muriese ante que heredase, si dexase fijo legitimo varón, que lo ouiese, pero si fincare otro fijo varón del rey que aquel lo herede et non el nieto" (MACDONALD: 1965; p. 651, nota 11, Apud: GONZÁLEZ JIMÉNEZ: 1996-1997; p. 203). Diante das constatações de MacDonald, Manuel González Jiménez (1996-1997; p. 203) pergunta: “QQué sentido tendría esta manipulación del texto de las Partidas si no hubiesen tenido vigencia de ley?" Evidentemente, nenhum, para ele. González Jimenez também cita com propriedade Jerry Craddock (1986), que em seus estudos sobre a mesma interpolação, realizada provavelmente em 1276, observou que também havia sido alterada no código a idade legal fixada para poder reinar, diminuindo de vinte para R. Fac. Dir. UFG, v. 40, n.2, p. 92-110, jul. / dez. 2016 ISSN 0101-7187 
dezessete anos, precisamente a mesma que tinha então o infante Sancho. Evitava-se, assim, a ocorrência de regência, caso o rei viesse a falecer (O'CALLAGHAN: 1996; p. 284).

Assim, parece-nos ser correto afirmar que as Partidas estavam em vigor no período de Afonso X. Contudo, particularmente no processo da sucessão do rei Sábio, suas leis não foram aplicadas, permaneceram no campo do ideal. Conforme apresentaremos, na prática, a sucessão do rei Sábio se deu pela força e pelo poder da tradição. Isso pode ser verificado nos relatos contidos na Crónica del Rey Don Alfonso Décimo, na qual são narrados os feitos do rei e a vida da corte durante reinado do rei Sábio.

\section{O PROBLEMA SUCESSÓRIO NA CRÓNICA DEL REY DON ALFONSO DÉCIMO}

A Crónica del Rey Don Alfonso Décimo ${ }^{6}$ apresenta uma narrativa sobre o processo sucessório iniciado com a morte de Fernando de la Cerda. Antes de tudo, afirma a legitimidade do príncipe herdeiro. Os primeiros relatos que apresentam Fernando como herdeiro de Afonso $\mathrm{X}$ são aqueles que se referem ao nascimento e ao casamento do príncipe. Sobre o nascimento, a crônica informa que dez meses após o nascimento da primeira filha do rei, chamada Dona Berenguela, Dona Violante, mulher de Afonso X, deu à luz uma criança do sexo masculino que recebeu o nome de Fernando, fijo primero heredero del Rey Don Alfonso (CrAX; p. 5). Sobre o matrimônio do príncipe, é apresentada a preocupação de Afonso X em providenciar o casamento do seu primogênito. Segundo o cronista, vendo que Fernando estava com a idade de se casar, Afonso X enviou emissários ao rei Luís, da França (1226-1270), propondo o casamento do infante com sua filha, Dona Blanca (CrAX; p. 12). ${ }^{7} \mathrm{O}$ matrimônio foi acordado e o monarca francês enviou sua filha a Castela para casar-se com Fernando, o herdeiro de Afonso X, em 1269. Dona Blanca foi a Castela acompanhada por seu irmão Don Felipe, o sucessor do rei Luís da França. Essas notícias apresentadas na Crónica del Rey Don Alfonso Décimo deixavam claro que Fernando era o herdeiro e sucessor de Afonso X, e, também, especificavam a prática sucessória do além Pirineus: na França a sucessão também ocorria via hereditariedade, sendo o primeiro filho o herdeiro. ${ }^{8} \mathrm{Da}$ mesma forma, esses relatos, além de explicitarem a primazia do filho sobre a filha e confirmarem que Fernando era o herdeiro de Afonso X, apresentam o casamento como uma das principais formas de aliança entre os reinos medievais. Aliança que, no caso específico de Castela, muito influirá no processo de sucessão 
do rei Sábio. Após o matrimônio, Fernando de la Cerda e Blanca tiveram dois filhos legítimos e para o primogênito, também chamado de Afonso, buscaram garantir a herança do trono castelhano.

De acordo com a Crónica del Rey Don Alfonso Décimo, em 1275, em virtude de uma viagem de Afonso X, a Beaucaire, França, onde iria tratar com o Papa Gregório X (12711276) a respeito da sua candidatura à eleição do Império, o príncipe Fernando ocupou a regência do reino. Enquanto era regente, ocorreu a invasão dos benimerines e coube a Fernando a responsabilidade pela proteção do reino, o que fez direcionando-se juntamente com as forças castelhanas para a fronteira com al Andalus, visando enfrentar o inimigo que se aproximava. No entanto, estando em Villa Real, o príncipe adoeceu. Sentindo-se próximo da morte, solicitou a Juan Nuñez de Lara, membro do Conselho Real, que fizesse com que seu filho primogênito, Afonso, fosse reconhecido como seu herdeiro. Dessa maneira, visava garantir a seu filho o direito à sucessão de Afonso $\mathrm{X}$ - se assim fosse, o reino de Castela teria como rei um neto de Afonso X e do futuro São Luis, rei da França (CrAX; p. 51).

Com a morte do primogênito de Afonso X, Fernando, o segundo filho do rei Sábio, o futuro Sancho IV, pleiteou o direito à sucessão do trono castelhano e deu início aos conflitos que se prolongariam no tempo. Como observa Fernando Arias Guillén (2012), a tradição castelhana favorecia o irmão de Fernando, Sancho, pois, desde a sucessão de Sancho II, morto em 1072, os irmãos menores haviam herdado o reino no caso de falecimento do primogênito. Assim, com a morte de Fernando, o direito de herança ao trono castelhano deveria ser passada ao segundo filho homem de Afonso X, Sancho, e não aos herdeiros do infante morto. Contudo, não era isso que estabelecia as Partidas, especificamente na Segunda Lei do Título XV anteriormente citada.

De acordo com as leis das Partidas, o príncipe Fernando, mesmo que tenha morrido antes de assumir o trono, transmitiria a herança a seu primogênito, e foi isso o que buscou fazer em seu leito de morte. Certamente, Fernando conhecia as intenções de seu irmão e sabia que sua morte abriria uma disputa pelo trono, o que não tardou acontecer. Como afirma Arias Guillén (2012; p. 148),

Mientras que Juan Núñez de Lara se comprometió ante el agonizante Fernando a criar a su hijo, Alfonso, y defender sus derechos al trono como sucesor del rey Sabio, el otro gran magnate del reino, Lope Díaz de Haro, se vinculó al infante Sancho, para que fuera este quien heredase la corona. 
Após saber do falecimento de Fernando, ocorrido em 24 de julho de 1275, o infante Sancho, desconhecendo ou desprezando as leis elaboradas a pedido de seu pai entre os anos de 1255 e 1265, entrou em conversações com membros do Conselho Real, dentre os quais estava Lope Diaz de Haro, e deixou afirmado que, com a morte de Fernando, ele era o mais velho dos seus irmãos e, portanto, deveria herdar os reinos após a morte de seu pai (CrAX; p. 51).

A atuação de Sancho abriu a disputa pela sucessão ao trono por dois grupos distintos. De um lado estavam Sancho e os seus partidários, representados principalmente por Lope Diaz de Haro e, do outro lado, estavam os filhos de Fernando, protegidos por Juan Nuñez de Lara, Dona Violante - esposa de Afonso X -, Dona Blanca - esposa de Fernando e mãe do primogênito - e Felipe III - rei da França e tio dos filhos de Fernando.

É importante destacar que, no início da disputa pela sucessão, Afonso X estava fora dos domínios do reino castelhano, e quando voltou já era forte a adesão dos ricos-homens ao partido de Sancho. De acordo com a Crónica del Rey Don Alfonso Décimo, esses aristocratas haviam sido influenciados pela campanha preparada por Lope Díaz de Haro, teria orientado Sancho a dizer a todos que estavam em Villa Real que, na ausência de seu pai e do seu irmão, ele desejava proteger a fronteira que naquela ocasião estava sendo ameaçada pelas forças benimerines. Para tanto, pedia aos poderosos do reino que o ajudasse indo com ele para frente de batalha, garantindo, assim, a proteção do reino. A estratégia de Lope Díaz de Haro tinha como principal objetivo alcançar o apoio de Afonso $\mathrm{X}$ e dos nobres castelhanos às pretensões de Sancho. Por um lado, proporcionaria que Afonso X visse em Sancho o desejo de proteger o reino castelhano, e com esse reconhecimento o tornasse seu legítimo herdeiro. Por outro lado, faria com que os poderosos do reino passassem a ter confiança nele, mediante o explicito desejo de proteger o reino frente aos inimigos e, dessa maneira, os ricos homens castelhanos não ofereceriam obstáculos ao reconhecimento de Sancho como o herdeiro e sucessor do rei. ${ }^{9}$ Esse acordo estabelecido entre Sancho e Lope Díaz de Haro, além de ser um exemplo das estratégias utilizadas pela nobreza do século XIII para alcançar os benefícios que podiam ser oferecidos pelo rei, mostra um jogo de interesses, que colocava-se acima da lei, pois, conforme definido na Lei 2 do Título XV da Segunda Partida, os legítimos herdeiros e sucessores de Afonso X, eram os filhos de Fernando com Dona Blanca. Percebe-se também nesse acordo a preocupação em construir uma imagem ideal para Sancho como futuro rei de Leão e Castela.

A atuação de Lope Díaz de Haro é exemplar das tramas da nobreza em torno das questões sucessórias. Com o retorno de Afonso X a Castela, Lope Díaz de Haro, apoiado pelos 
poderosos do reino, pediu ao rei que reconhecesse Sancho como herdeiro do trono de Leão e Castela. Como resposta, o rei Sábio convocou o Conselho para tratar sobre a questão. É no relato referente ao comportamento dos conselheiros que percebemos a existência de uma preocupação quanto à desobediência da lei referente à sucessão:

E todos los que estaban y dubdaron mucho en este consejo, é Don Manuel dijole: 'Señor, el arbol de los reyes non se pierde por postura, nin se desereda por y al que viene por natura, é si el mayor que viene de árbol fallesce, debe fincar la rama de so El en somo; é tres cosas son que non son so postura, ley, ni Rey, ni reino; é cosa que sea fecha contra cualquiera desta, non vale nin deve ser tenida nin guardada. (CrAX; p. 53).

Embora D. Manuel, irmão do rei, tenha afirmado a importância do respeito à lei, ao rei e ao reino, Afonso X, em detrimento das leis contidas nas Partidas e dos direitos do seu neto, o legítimo herdeiro, declarou o infante Sancho seu sucessor (CrAX; p. 53). ${ }^{10} \mathrm{O}$ cronista procura mostrar que Afonso X aceitou reconhecer Sancho como seu sucessor levando em consideração a liderança exercida por ele, principalmente, contra os benimerines, ocorrida durante o período em que esteve fora de Castela.

\section{UNIDADE DO REINO E LEGITIMIDADE DO PODER NA CRÓNICA DEL REY DON ALFONSO DÉCIMO}

Mesmo após a definição de Sancho como herdeiro do trono, as relações entre pai e filho foram se deteriorando ao longo dos anos e, em várias ocasiões, Afonso X e Sancho se enfrentaram em disputas políticas. Um dos principais motivos dos conflitos se relacionava ao destino dos filhos do falecido príncipe Fernando, os Infantes de la Cerda, Afonso e Fernando, que estavam em poder de Pedro III, rei de Aragão, depois de tentarem fugir de Castela com sua mãe e sua avó. Embora Sancho tenha conseguido o apoio - muitas vezes por meio da violência - de importante parcela da aristocracia do reino, a presença de seus sobrinhos era uma ameaça constante. Além de representavam uma importante arma para os opositores de Sancho dentro do próprio reino, o status dos Infantes de la Cerda podia ser usado para justificar intervenções externas na política dos reinos de Leão e Castela, expressadas principalmente pelo rei francês, tio dos Infantes. Essas intervenções do rei francês concretizaram-se em diferentes momentos. Por exemplo, ao saber que os Infantes de la Cerda haviam sido, a mando de Sancho, feitos prisioneiros no Castelo de Xativa, Felipe III interveio solicitando a Afonso X que fosse dado a 
Afonso, filho primogênito de Fernando, o reino de Jahen, tornando-o vassalo dele e de Sancho. ${ }^{11}$ Em princípio, Afonso $\mathrm{X}$ cedeu ao pedido do rei francês.

A atitude vacilante de Afonso X, ora reconhecendo Sancho como legítimo herdeiro, ora atendendo as solicitações dos partidários dos filhos de Fernando, somada ao desconhecimento da reprovação das Cortes em relação a sua atuação diante do rei francês, propiciaram o aumento e o fortalecimento dos partidários de Sancho. Em 1282, Sancho rebelouse contra seu pai e enviou mensagens para todo o reino castelhano colocando-se como defensor da terra frente às injustiças praticadas por Afonso X. Nessa ocasião recebeu apoio de vários ricos homens, especialmente dos Haro. Em resposta, Afonso X deserdou publicamente Sancho, embora isso não apareça na Crónica del Rey Don Alfonso Décimo.

$\mathrm{Na}$ sua narrativa, o cronista buscava demonstrar que a rivalidade era maior entre os partidários do rei e de Sancho do que entre pai e filho. Isso fica evidente no relato da reação de Afonso X diante da notícia da morte de Sancho, transmitida em uma carta. Segundo a crônica, ao saber da morte de Sancho, Afonso X foi tomado pela tristeza e dirigiu-se sozinho a um quarto. Quando viram que o rei estava isolado, entenderam que estava muito triste pela morte do filho. Um dos seus privados, contudo, atreveu-se a entrar no quarto e questionar o rei, perguntando-lhe porque sofria pelo filho que havia deserdado. Tal privado aconselhou ao rei que os poderosos não poderiam perceber que ele sofria pela morte de Sancho, pois isso faria com que seus aliados se revoltassem contra ele. Então, para disfarçar o real motivo da dor, o rei Sábio teria dito:

\footnotetext{
Maestre Nicolas: non lloro yo por el infante Don Sancho, mas lloro por mi, mezquino Viejo que pues él muerto es, nunca yo cobraré los mis reinos, ca tamaño es el miedo que tomaron de mi los de las Villas é todos los ricos omes é las ordenes por el yerro que me ficieron, que nem se me querran dar, é mas aina los cobrará yo del infante Don Sancho si viviera, que era uno, que no de tantos"... (CrAX; p. 65-66). ${ }^{12}$
}

No entanto, a notícia registrada na carta revelou-se uma mentira, pois Sancho se recuperou da grave doença que tinha originado o mal-entendido. Sancho estava vivo, mas o cronista utilizou o episódio para demonstrar que Afonso X visualizava na figura de seu filho Sancho a preservação da unidade do reino. Essa percepção teria levado o rei Sábio a definitivamente reconhecê-lo como o seu herdeiro e sucessor, independente da lei e da atuação daqueles nobres que se posicionavam contra os interesses de Sancho. Mantinha-se com essa atitude a unidade do reino. 
Embora tenha conseguido um significativo enfraquecimento do poder de Afonso X - que ficou circunscrito à Sevilha -, a oposição papal e a perda de importantes aliados levou Sancho a procurar restabelecer a paz com seu pai, restituindo-lhe o trono em troca de ser novamente declarado seu herdeiro. O rei Sábio morreu sem revogar sua decisão, contudo, a Crónica del Rey Don Alfonso Décimo, em uma visão tendenciosa, afirma o reconhecimento e o perdão concedido pelo pai ao filho. O restabelecimento da paz entre pai e filho é apresentado pelo cronista ao relatar a morte de Afonso X, e serve para legitimar o direito de Sancho como senhor do reino. Nesse relato busca demonstrar que, diante dos interesses de alguns integrantes da família do rei Sábio, a preservação da unidade do reino era algo totalmente incerto. Por exemplo, segundo o cronista, Don Juan, filho mais novo de Afonso X, havia solicitado ao rei que lhe desse o reino de Sevilha e de Badajoz, com todas as vilas que esses reinos possuíssem. Demonstrava-se, assim, que Don Juan não pensava na integridade do reino, mas sim em interesses próprios. Nesse sentido, é significativo o posicionamento do rei Sábio diante dessa solicitação: ao dizer não a Don Juan e ao confirmar Sancho como herdeiro, preservará a unidade do reino existente desde Fernando III, seu pai. ${ }^{13}$ Contudo, sabemos que a resposta dada por Afonso $\mathrm{X}$ ao filho Juan foi oposta à relatada na Crónica. Antes de falecer, o rei Sábio, em uma disposição testamentária, concedeu a Juan os reinos de Sevilha e Badajoz, desfazendo assim a unidade do reino existente até então. Porém, Sancho nunca cumpriu essa designação deixada por seu pai, gerando como isso mais problemas a serem enfrentados por ele ao longo do seu reinado (PAREDES NUÑEZ: 1996; p. 241).

Ao ocultar o testamento de Afonso $\mathrm{X}$ e apresentar versões próprias dos acontecimentos relacionados ao seu governo e à transmissão de sua herança, o cronista revela o interesse em manipular a história visando alcançar objetivos precisos. Sancho representava o poder centralizador objetivado pela monarquia castelhana, que, na época em que foi escrita a crônica - durante o reinado de Afonso XI -, visava manter e conservar o poder nas mãos da realeza, tendo que, para tanto, lidar com os conflitos e interesses da nobreza. O registro da legitimidade dos direitos de Sancho como herdeiro de Afonso X na Crónica del Rey Don Alfonso Decimo está inserido nesse esforço de garantir para a monarquia a centralização do poder. Assim, para compreendermos o significado da narrativa sobre a sucessão de Afonso X na Crónica del Rey Don Alfonso Décimo é fundamental destacarmos o contexto em que ela foi escrita. Nesse aspecto, destacaremos o papel desempenhado pela história como meio de deixar 
registrado e documentado informações valiosas, consideradas como verdadeiras, que davam sustentação e legitimidade a situações vigentes no momento de sua elaboração, garantindo, dessa maneira, a continuidade, de forma legítima, de algo cujo início tinha sido objeto de contestação.

\section{A CRIAÇÃO E O REGISTRO DE UMA MEMÓRIA LEGITIMADORA}

Segundo Cayetano Rosel (1953), editor da Crónica del Rey Don Alfonso Décimo, essa é a primeira crônica contida no Códice das Três Corónicas. As outras duas são a de Sancho IV - sucessor de Afonso X - e a de Fernando IV - filho e sucessor de Sancho IV. A autoria dessas Crônicas foi atribuída pelo erudito José Pellicer a Fernando Sanchez de Tovar, fidalgo de Valladolid, jurista célebre, primeiro alcaide da Casa Real, notário do reino de Castela, embaixador duas vezes da corte de Roma e uma da francesa, chanceler do selo da autenticidade e conselheiro de Afonso XI (1312-1350). A origem e as atividades do cronista nos auxiliam no entendimento sobre a obra e contribui para a nossa percepção do momento histórico vivido em Castela no momento de elaboração da crônica. A crônica histórica da baixa Idade Média é um texto narrativo, construído a partir da retomada de modelos antigos e de pressupostos de uma tradição literária cristã. Escrita com a intenção de verdade, tinha o objetivo de perpetuar a memória de um reinado, legitimar seus promotores e oferecer exemplos para a sociedade política (GUIMARÃES: 2012, p. 70; SESMA MUÑOZ: 2003).

Escrita no século XIV pelo conselheiro de Afonso XI, a Crónica del Rey Don Alfonso Décimo revela as preocupações políticas do momento: o desejo de manter a unidade do território, garantir a institucionalização da monarquia como forma de governo e afirmar a legitimidade de Sancho IV e de seus sucessores, especialmente Afonso XI. ${ }^{14}$ Assim, a crônica não trata exclusivamente de Afonso X e dos seus feitos, mas, de forma mais ampla, do reino de Castela e Leão no período de 1252 a 1284, tendo como foco de destaque a atuação de Sancho IV, avô de Afonso XI, que reinava no momento da sua elaboração. Ao enfatizar o reconhecimento de Sancho IV como legítimo herdeiro de Afonso X, o cronista pretendia afirmar a autoridade de Afonso XI, legitimando-o em um cenário de disputas pelo poder que marcou tanto o seu reinado como o de seus antecessores. Como já destacado, a legitimidade da linhagem à qual Afonso XI pertencia esteve ameaçada durante o reinado de Sancho IV (12841295) pelos partidários dos filhos de Fernando, Afonso e Fernando, os Infantes de la Cerda,

R. Fac. Dir. UFG, v. 40, n.2, p. 92-110, jul. / dez. 2016

ISSN 0101-7187 
representados especialmente por Juan Nuñez de Lara. ${ }^{15}$ Durante o reinado de Fernando IV (1295-1312) - filho e sucessor de Sancho IV e pai de Afonso XI -, a ameaça ocorreu por parte de Afonso de la Cerda, que, unido ao filho do rei de Aragão, o príncipe Dom Pedro, e seus partidários, entrou em Castela e declarou-se rei. ${ }^{16}$ Os conflitos sucessórios com a participação dos Infantes de la Cerda estenderam-se também durante a menoridade de Afonso XI, colocando em risco o poder desse rei. Nesse contexto de ameaças frequentes, a crônica servia como instrumento usado para afirmar a legitimidade do poder de Sancho IV e consequentemente de Afonso XI e de seus sucessores.

Por meio da Crónica del Rey Alfonso Décimo buscava-se registrar a história de forma a garantir a legitimidade de Sancho IV, de Fernando IV e de Afonso XI. Especialmente para Afonso XI, a afirmação da legitimidade da sua linhagem era fundamental, pois, durante seu reinado, as Siete Partidas, código que durante o reinado de Afonso X era apenas uma teoria, tornou-se na prática a legislação do reino de Castela e Leão, embora de forma parcial, devido à resistência da nobreza em deixar os "fueros" locais que a privilegiavam. As Siete Partidas, ao estabelecer e justificar "quem é o rei", "quem pode ser rei" e como se dava o processo de sucessão, caracterizou e definiu a monarquia como instituição de governo em Castela e Leão, território unificado primeiramente por Fernando III, o Santo, ao herdar Castela em 1217 e Leão em 1230, e mantido por seu filho, Afonso X.

No entanto, Afonso XI, de acordo com a lei por ele colocada em vigor, não teria direito a ser o representante da Coroa no reino de Castela e Leão. Assim, para justificar e legitimar esta situação, a história seria fundamental. Por meio das crônicas elaboradas durante seu reinado (1312-1350), foi apresentada a história do reino de forma a dar continuidade à Primera Crónica General de España, elaborada sob a orientação de Afonso X, resgatando, dessa forma, a antiguidade do reino. Na Crônica relativa ao reinado de Afonso X, buscou-se justificar e legitimar o direito sucessório de Sancho IV, avô de Afonso XI. Os principais argumentos utilizados foram o perdão concedido por Afonso X ao seu filho Sancho IV, e a vontade de Deus, como expressado nas palavras que o cronista atribuiu a Sancho IV dirigindose a seu pai:

Señor, non me fecistes vos, mas fizome Dios, é fizo mucho por me facer, ca mato a mi hermano, que era mayor que yo, é que era vuestro heredero destos reinos, si el viviera mas que vos é non lo mato por al, si non porque lo heredase yo despues de vuestros dias (CrAX; p. 60) 
Interpretação semelhante já havia aparecido na obra Castigos e Documentos del Rey Don Sancho, elaborada durante o reinado de Sancho IV (1284-1295), onde se diz:

\begin{abstract}
É Nós el Rey Don Sancho, por la gracia de Dios, que fecimos este libro, heredamos los regnos que habia nuestro padre, el Rey Don Alfonso, porque el infante Don Fernando que era mayor que nos seyendo él casado é habiendo fijos, morió grand tiempo ante que el Rey nuestro padre finase, ca si él un dia visquiera mas que nuestro padre, non habiéramos nos ningund derecho en el regno. Mas ordenamiento fué de Dios que fuese así,é á lo que él ordena non puede ni debe pasar ninguno contra ello, ca el es aquel que sabe es lo que face (CastDoC; p. 119).
\end{abstract}

O direito à sucessão, concedido a Sancho IV pela vontade de Deus, foi um discurso criado e reforçado principalmente no seu reinado, e seu principal objetivo era esconder o predomínio da força sobre a lei. Essa pretensão também está presente nas crônicas de Sancho IV, Fernando IV e do próprio Afonso XI. Nessas obras, embora fossem apresentados relatos sobre a contestação da linhagem reinante pelos Infantes de la Cerda - legítimos herdeiros segundo a lei -, enfatizou-se a capacidade de fazer justiça e de liderar o combate contra os muçulmanos - ameaça constante contra a segurança do reino - como elemento legitimador do poder de Sancho IV e de sua linhagem régia.

\title{
6 CONCLUSÃo
}

A sucessão de Afonso X, o Sábio, foi um processo controverso, marcado por conflitos entre o Rei, seus descendentes e os ricos homens de Leão e Castela, e que envolveu personagens externos como o rei da França e o Papa. Nesse contexto de disputas, a resolução dos conflitos e as decisões tomadas colocaram em choque as definições jurídicas elaboradas durante o reinado de Afonso X e a tradição e a prática política de concorrência pelo trono. $\mathrm{O}$ pleito sucessório em questão iniciou-se com a morte do príncipe Fernando, filho primogênito e herdeiro de Afonso X, deixando dois filhos legítimos, Afonso e Fernando, os Infantes de la Cerda. De acordo com as Siete Partidas, especificamente a Lei 2 do Título XV da Segunda Partida, com a morte do príncipe, mesmo antes de receber a herança, o direito ao trono seria transmitido a seu primogênito, Afonso de la Cerda. Contudo, o segundo filho de Afonso X, o futuro Sancho IV, pleiteou a herança e, aliado a uma poderosa facção da nobreza castelhana representada pelos Haro, conquistou o trono. A disputa pela sucessão e a definição de Sancho como herdeiro de Afonso X revelam um conflito entre teoria e tradição. Por um lado, as leis da 
Segunda Partida orientavam que a herança pertencia aos Infantes de la Cerda. Por outro, uma tradição indicava que com a morte do primogênito a herança poderia passar aos irmãos menores, o que favoreceu a reivindicação de Sancho IV. Embora tenha conquistado o trono, a legitimidade de Sancho IV foi colocada em questão e afetou o reinado de todos os seus descendentes. Foi necessária a construção de uma história que afirmasse e divulgasse a legitimidade dessa linhagem, o que se concretizou no reinado de Afonso XI com a escrita da Crónica del Rey Don Alfonso Décimo. Ao explicitar o confronto entre a teoria referente à sucessão real elaborada sob a direção de Afonso X, o Sábio, com o processo de sucessão deste mesmo rei, a Crónica del Rey Don Alfonso Décimo revela, por um lado, a importância das Siete Partidas como código jurídico vigente e, por outro lado, o uso político da crônica baixo medieval como instrumento de perpetuação de memória e legitimação de poder.

\section{REFERÊNCIAS}

ALFONSO X, El Sabio. Partida Segunda. Madrid: Publicaciones Españolas, Tomo I, 1961. BIBLIA de Jerusalém. São Paulo: Paulus, 1995.

PRIMERA Crónica General de España. Que mando componer Alfonso el Sabio y que se continuaba bajo Sancho IV em 1289. MENÉNDEZ PIDAL, Ramón (ed.) Madrid: Gredos, 1955.

CRÓNICA del Rey Don Alfonso Décimo. In: CAYETANO ROSELL (org.). Crónicas de los Reyes de Castilla. Madrid: Atlas, 1953. (Biblioteca de Autores Españoles, 66)

CRÓNICA del Rey Don Fernando IV. In: CAYETANO ROSELL (org.) Crónicas de los Reyes de Castilla. Madrid: Atlas, 1953. (Biblioteca de Autores Españoles, 66)

CRÓNICA del Rey Don Sancho. In: CAYETANO ROSELL (org.). Crónicas de los Reyes de Castilla. Madrid: Atlas, 1953. (Biblioteca de Autores Españoles, 66)

BERMEJO CABRERO, José Luis. García-Gallo ante la obra legislativa de Alfonso X. Cuadernos de Historia del Derecho, 18, p. 163-191, 2011.

CRADDOCK, Jerry R. Dynasty in Dispute: Alfonso X el Sabio and the Succession to the Throne of Castile and León. In History and Legend. Viator, 17, p. 197-219, 1986.

R. Fac. Dir. UFG, v. 40, n.2, p. 92-110, jul. / dez. 2016

ISSN 0101-7187 
Lei, Tradição E Memória Na Controversa Sucessão De Afonso X (1252-1284)

GARCÍA-GALLO, Alfonso. La obra legislativa de Alfonso X. Hecho e hipóteses. Anuario de Historia de del Derecho Español, n. 54, p. 97-161, 1984.

GONZÁLEZ JIMÉNEZ, Manuel. La sucesión al trono de Castilla: 1275-1304. Anales de la Universidad de Alicante. Historia medieval, ISSN 0212-2480, n. 11, 1996-1997. (Ejemplar dedicado a: Actas del Congreso Internacional "Jaime II, 700 años después", coord. por Juan Antonio Barrio Barrio, Jose Vicente Cabezuelo Pliego, Juan Francisco Jiménez Alcázar), p. 201-212.

MACDONALD, R. S. Alfonso the Leamed and Succession: A Father's Dilemma, Speculum. Apud: GONZÁLEZ JIMÉNEZ, Manuel. La sucesión al trono de Castilla: 1275-1304. Anales de la Universidad de Alicante. Historia medieval, n. 11, p. 201-212, 1996-1997.

MARTÍNEZ MARINA, F. Ensayo histórico critico sobre la antigua legislación y principales cuerpos legales de los Reynos de León y Castilla y especialmente sobre el Código de don Alfonso el Sabio conocido con el nombre de las Siete Partidas. Madrid, 1808; 4 ed. Madrid: Atlas, 1966. (Biblioteca de Autores Espanoles, 194)

NIETO SORIA, José Manuel. Fundamentos Ideologicos del Poder Real em Castilla (siglos XIII-XIV). Madrid: Ediciones de la Universidad Complutense, 1988.

O'CALlAGHAN, Joseph F. El rey Sabio. El reinado de Alfonso X de Castilla. Sevilla: Universidad de Sevilla, 1996.

PAREDES NUÑEZ, JUAN. Sancho IV y su tiempo en la literatura genealógica peninsular. In: ALVAR, Carlos; LUCIA MEGÍAS, Jose Manuel (ed.) La Literatura em la época de Sancho IV. Alcalá de Henares: Universidad de Alcalá, 1996.

PIZARRO DIAS, Nuno. O dilema de Alfonso X. Revista da Faculdade de Letras. História, série II, vol. 15, n. 2, p. 1345-1360, 1998. Disponível em: http://ler.letras.up.pt/uploads/ficheiros/4061.pdf. Acesso: 12 abr. 2016.

SESMA MUÑOZ, José Angel. La creación de la memória histórica: uma selección interesada del pasado. In: IGLESIA DUARTE, José Ignácio de la (coord.) Memoria, Mito y Realidad en la Historia Medieval. XIII Semana de Estudios Medievales Nájera 2002. Logroño: Instituto de Estudios Riojanos, 2003, p. 13-32. 
${ }^{1}$ A obra de Afonso X, de forma geral, e as Siete Partidas, de forma específica, foram objeto de muitos estudos e dispensam maiores apresentações. Um trabalho pioneiro e indispensável realizou F. Martínez Marina (1966) no início do século XIX, cuja primeira edição data de 1808. Com posteridade, entre vários autores, destacam-se os textos de García-Gallo como referência fundamental para o estudo da obra legislativa de Afonso X. São muitas as referências e elencá-las extrapolaria os objetivos desse artigo. Para um balanço historiográfico, sugerimos o artigo do próprio García Gallo, La obra legislativa de Alfonso X. Hecho e hipóteses, publicado no Anuario de História del Derecho Español, (1984), bem como o artigo de José Luis Bermejo Cabrero (2011).

${ }^{2}$ Elaborada durante o reinado de Afonso X, na segunda metade do século XIII, e publicada no século XX, em 1961. Para evitar as discrepâncias entre as datas de elaboração da obra e da sua publicação, a partir de agora utilizaremos SegPart nas referências das citações.

${ }^{3}$ É importante destacarmos que uma das maiores aspirações de Alfonso X, o Sábio, era obter o título de Imperador do Sacro Império Romano Germânico.

${ }^{4}$ É significativo, no entanto, termos em mente as palavras do profeta Samuel, ao apresentar ao povo de Israel o inconveniente de se ter um rei. Segundo Samuel: "Este é o direito do rei que reinará sobre vós: Ele convocará os vossos filhos e os encarregará dos seus carros de guerra e dos seus cavalos e os fará correr à frente do seu carro; e os nomeará chefe de mil e chefes de cinqüenta; e os fará lavrar a terra dele e ceifar a sua seara, fabricar as suas armas de guerra e as peças de seus carros. Ele tomará as vossas filhas para perfumistas, cozinheiras e padeiras. Tomará os vossos campos, as vossas vinhas, os vossos melhores olivais, e os dará aos seus oficiais. Das vossas culturas e das vossas vinhas ele cobrará o dízimo, que destinará aos seus eunucos e aos seus oficiais. Os melhores dentre os vossos servos e as vossas servas, os vossos bois e os vossos jumentos, ele os tomará para o seu serviço. Exigirá o dízimo dos vossos rebanhos, e vós mesmos vos tornareis seus escravos. Então naquele dia, reclamareis contra o rei que vós mesmos tiverdes escolhido, mas Iahweh não vos responderá, naquele dia" (SAMUEL, cap. 8 vers. 11 a 18, p. 429-30. In: BIBLIA de Jerusalém, 1995).

${ }^{5}$ Uma análise exaustiva da questão pode ser encontrada nos textos de José Luis Bermejo Cabrero (2011).

${ }^{6}$ A Crónica del Rey Don Alfonso Décimo foi escrita durante o reinado de Afonso XI (1312-1350) e publicada no ano de 1953. Para evitar conflitos entre as datas de elaboração e de publicação, a partir de agora utlizaremos CrAX, quando nos referirmos à obra.

${ }^{7}$ De acordo com a crônica: Veyendo que el infante Don Ferrando su fijo, primero heredero, era en tiempo de aver su mujer, seyendo en Toledo envio sus mandaderos al Rey Sant Luis de Francia, con quien Le envio rogar que Le diese su fija doña Blanca para que casase con su fijo el infante Don Ferrando... (CrAX; p.12). O casamento de Fernando e Blanca aconteceu em Burgos em 1269.

${ }^{8}$ E ainda: "E en este tiempo el Rey de Francia envio à Castilla á doña Blanca su fija para que casase com el infante Don Ferrando, fijo primero heredero deste Rey Don Alfonso, é vino con ella Don Felipe, su heredero, que fue Rey de Francia ..." (CrAX; p. 13).

${ }^{9}$ Conforme a crônica: "É los pleytos firmados por amos á dos desta guisa, Don Lope Díaz consejó al infante Don Sancho que fablase con todos aquellos que eran allí en Villa Real, é que les dijese que, pues el Rey Don Alfonso, su padre, non era en los reinos, é el infante Don Ferrando, su Hermano, era finado, que El queria ir defender la tierra, é que les mandase é rogase que fuese con El, é que Le servirian é Le ayudarian en manera que la frontera fuese amparada, entre tanto que el Rey su padre, ca entenderia que ovo voluntad de se parar á defender el reino, é que merescia heredarlo despues de sus dias, é otrosi ganaria los corazones de todos los de los reinos, é que teniam por derecho de Le rescibir por heredero después de dias de su padre; é que luego se llamase en sus cartas fijo mayor heredero" (CrAX; p. 51-52).

10 Segundo o cronista: "É el Rey mandóles que ficiesen pleito é menaje al infante Don Sancho su fijo primero heredero, que despues de dias del rey Don Alfonso que lo oviesen por su Rey" (CrAX, p. 53).

${ }^{11}$ Segundo o cronista: "É el Rey Don Alfonso, estando en Bayona, é todos sus fijos con él, él Rey de Francia vino de la outra parte ... é envio al príncipe de Morea... para tratar con el Rey Don Alfonso el pleito de avenencia de don Alfosno, fijo del infante don Fernando, é avialo llegado á logar que le diese el Rey Don Alfonso el reino de Jahen é que fuese su vasallo é del infante Don Sancho" (CrAX, p. 58-59).

12 Segundo o cronista: "É cuando el Rey Don Alfonso vió en la carta que descie que era muerto el infante Don Sancho, su fijo, tomo muy grand pesar... aportóse en una cámara solo... E cuando los de su casa vieron que asi estava apartado, entendieron que mostraba grand pesar por la muerte de su fijo, é atrevióse uno de los sus privados... é entro a la cámara á él, e dijole esta palabras: 'Señor, por que mostrades tan grand pesar por el infante Don Sancho, vuestro fijo, que vos tenia deseheredado? Ca si vos lo saben el infante Don Juan [filho do rei] é estos otros ricos omes que son aqui convusco, perderlos hedes todos, é tomaran alguna Carrera contra vós. É el por mostrar que non lloraba nin avia pesar por el infante Don Sancho, é encobrir que le non entendiesen que

R. Fac. Dir. UFG, v. 40, n.2, p. 92-110, jul. / dez. 2016 
mostraba pesar por él, dijo estas palabras: 'Maestre Nicolas: non lloro yo por el infante Don Sancho, mas lloro por mi, mezquino Viejo que pues él muerto es, nunca yo cobraré los mis reinos, ca tamaño es el miedo que tomaron de mi los de las Villas é todos los ricos omes é las ordenes por el yerro que me ficieron, que nem se me querran dar, é mas aina los cobrará yo del infante Don Sancho si viviera, que era uno, que no de tantos" (CrAX, p. 6566).

${ }^{13}$ Conforme a crônica: “... é veyendo que non podria guarir, el infante Don Juan demandóle que le mandase dar el reinado que non podria guarir, el infante Don Juan demandóle que le mandase dar el reinado de Sevilla é el de Badajóz con todos las otras villas que tênia... pero él non lo quiso facer. E cuando fué afincado de la dolência dijo ante todos que perdonaba al infante Don Sancho, su fijo heredero, que lo ficiera con mancebia é que perdonaba á todos los sus naturales de los reinos el yerro que ficieron contra él ..." (CrAX: p. 66).

${ }^{14}$ Elementos como a afirmação da língua castelhana e do patronato do apóstolo Tiago também contribuíram para as representações da unidade do reino e da legitimidade da linhagem régia. O castelhano tornou-se língua oficial, na qual foi relatada a história e escrita a legislação. Reafirmou-se a devoção a Santiago como Patrono dos castelhanos, e nas batalhas da Reconquista a senha para a guerra permaneceu sendo o grito Dios ayuda et Sanct Iago!

${ }^{15}$ Segundo a crônica “... Don Juan Nuñez, que era señor de Albarracin, facia guerra à Castilla contra este Rey Don Sancho con voz de Don Alfonso e Don Fernando, fijos del infante Don Fernando..." Crónica del Rey Don Sancho, publicada em 1953, p. 69. A partir de agora, CrSIV.

16 “... movió de Aragon Don Alfosno, fijo del infante Don Fernando, é el infante Don Pedro, fijo del Rey Don Pedro de Artagon [e seus partidários] é entraron por la tierra faciendo muy grand guerra, robando é quemando é matando é estragando cuanto fallaban ... é fueronse para Sant Fagunt ... é llamaron y á Don Alfonso, fijo del infante Don Fernando, Rey de Castilla, é de Toledo, é de Córdoba, é de Murcia é de Jahen ..." Crónica del Rey Don Fernando IV, publicada em 1953, p. 102. A partir de agora, CrFIV. 
Artigo recebido em 09 de setembro de 2016 e aceito em 22 de dezembro de 2016 